\title{
STUNTING, UNDERWEIGHT AND OVERWEIGHT: A MAJOR HEALTH PROBLEM AMONG CHILDREN UNDER 3 YEARS OF AGE IN URBAN AREAS OF WEST BENGAL, INDIA
}

\author{
Soumyajit Maiti ${ }^{1,3}$; Kausik Chatterjee ${ }^{1}$; Kazi Monjur Ali1 ${ }^{1}$; Debidas Ghosh ${ }^{1,2,3}$ and Shyamapada Paul2,3 \\ ${ }^{1}$ Department of Bio-Medical Laboratory Science and Management, (U.G.C. Innovative Funded Department) \\ Vidyasagar University, Midnapore - 721 102, West Bengal, India. \\ ${ }^{2}$ Nutrition \& Dietetics Unit, Department of Bio-Medical Laboratory Science and Management \\ Vidyasagar University, Midnapore - 721 102, West Bengal, India. \\ ${ }^{3}$ Rural Research Institute of Physiology \& Applied Nutrition (RRIPAN) \\ 'Gitanjali', Dr. Nilay Paul Road, Midnapore - 721 101, West Bengal, India.
}

\section{ABSTRACT}

Background: Malnutrition is still highly pervasive in developing countries, and pre-school age children may be a particular high-risk population. However, nutritional status of this group is poorly documented, particularly in urban areas.

Aims: To assess the stunting, underweight, thinness and overweight in urban Bengalee pre-school age children.

Methods: A total of 1060 children aged 1-3 years who attended the immunisation clinic of Midnapore District Red Cross Hospital of West Bengal, India during three years were enrolled in the study. The prevalence of underweight and stunting in pre-school age children were assessed using the SD classification based on the 2007 World Health Organization (WHO) child growth standards. The BMI classification was also used to assess thinness, overweight and obesity.
Results: Mean anthropometric variables were significantly higher among the boys than girls $(p \leq 0.05)$. The results showed that the prevalence of undernutrition, particularly stunting (50.9\%), was much higher than underweight (28.6\%). The prevalence of underweight was more pronounced among boys. Conversely, girls tended to be more stunted than boys. The study revealed that approximately $14.4 \%$ of pre-school age children were overweight and that boys (16.6\%) exhibited more overweight compared to girls (11.8\%). The study also indicated the co-occurrence of stunting and overweight among the participants.

Conclusions: The present study emphasised that malnutrition is a growing public health issue, regardless of as stunting and overweight were highly prevalent among the Bengalee pre-school age children in urban areas of West Bengal.

Key Words: Stunting, Underweight, Overweight, Preschool, Urban

\section{INTRODUCTION}

In developing countries, the increasing prevalence of obesity along with the perseverance of undernutrition is referred to as the 'Double Burden of Malnutrition' (DBM) ${ }^{[1]}$ In spite of the economic escalation of these countries, malnutrition is still highly prevalent, especially undernutrition. ${ }^{[2]}$

India represents a typical scenario in South-Asia, fitting the adage of the 'Asian Enigma' ${ }^{[3]}$ where progress in childhood malnutrition seems to have sunken into an apparent undernutrition trap. ${ }^{[4]}$ As per the latest estimates provided by the National Family Health Survey-3 (NFHS-3), the high overall levels of child undernutrition in India and its prevalence vary widely across the states and also across rural and urban areas. ${ }^{[5]}$ Conversely, recent evidence suggests that overweight persist during the pre-school age children in India ${ }^{[6-8]}$ and elsewhere. ${ }^{[9-12]}$ In general, children living under better socio-economic conditions have consistently exceeded their counterparts living under worse conditions in growth and maturation, as an individual's genetic endowment can better manifest itself under better environmental circumstances. ${ }^{[13]}$

Children are a critical resource whose growth and wellbeing will determine to a large extent a country's social and economic future. ${ }^{[8]}$ Pre-school age children are one of the most nutritionally vulnerable segments of the population. Nutrition during the first five years not only has an impact on growth and morbidity during childhood, but also acts as a determinant of nutritional status in adolescent and adult life. ${ }^{[14]}$ Considerable evidence suggests that malnutrition affects human performance, health and survival, including physical growth, morbidity, mortality, cognitive development, reproduction, physical work capacity and risks for several adult-onset chronic diseases. ${ }^{[15]}$ 
Assessment of growth is the single most important measurement for defining the nutritional and health status of children and provides an indirect measurement of the quality of life of the entire population. ${ }^{[16]}$ The World Health Organization (WHO) has been monitoring child growth and malnutrition since 1986 and collecting data in the Global Database on Child Growth and Malnutrition, which aims to facilitate international comparison, the identification of populations in need, the evaluation of national public health interventions, and monitoring trends in child growth. ${ }^{[17]}$ Therefore, an appraisal of a country's progress in healthcare can be made with the aid of growth studies. ${ }^{[8]}$ In this respect, pre-school age children are the main target group for strategies and actions to fight malnutrition.

Significant published data are available ${ }^{[8,18-20]}$ on the prevalence of undernutrition among pre-school age children in different parts of India, but mostly for rural sectors. However in contrast, there is a paucity of studies in urban pre-school age children of West Bengal. In this context, this study has attempted to assess the prevalence of stunting, underweight and overweight among preschool children of under 3 years old.

\section{MATERIALS AND METHODS}

\section{Settings}

The present cross-sectional study was conducted among the urban pre-school age children of Bengalee ethnicity attending an immunisation clinic in Midnapore District Red Cross Hospital situated at Midnapore town, West Bengal, India. Midnapore is a district town, located at $22.25^{\circ} \mathrm{N}, 87.65^{\circ} \mathrm{E}$ and is 23 meters above sea level. A total of 1060 children between the ages of 1-3 years participated in the study from January 2010 to December 2011. Data on age, sex, height and weight were recorded. A pro forma was designed to collect information on familial background. Household socio-economic and demographic variables such as father's occupation, family income and family size were included.

\section{Anthropometric measurements}

To assess the nutritional status of pre-school age children, anthropometric measurements, i.e., height and weight, were taken according to standard procedures describe by WHO. ${ }^{[22]}$ Weight was measured to the nearest $0.1 \mathrm{~kg}$ on a weighing scale with children wearing no shoes and only light clothing. Individual height was measured to the nearest $0.1 \mathrm{~cm}$ with a wooden stadiometer placed on a flat surface. BMI was calculated from the formula weight/ height ${ }^{2}\left(\mathrm{~kg} / \mathrm{m}^{2}\right)$.

\section{Nutritional assessment}

Nutritional assessment was carried out by using 2007 WHO Child Growth Standards ${ }^{[23]}$ according to the standard deviation (SD) classification. Children who were more than $2 \mathrm{SD}$ values below the reference median $(<\mathrm{Me}-$ dian -2 SD) on the basis of weight-for-age, height-for-age and BMI-for-age indices were classified as 'underweight', 'stunted' and 'thinness', respectively, and children who were more than $3 \mathrm{SD}$ values below the references median (Median -3 SD) were classified as 'severe underweight', 'severe stunted' and 'severe thinness', respectively. The overweight and obesity were defined as BMI-for-age above +1 and +2 SD scores, respectively.

\section{Ethical clearance}

The objective of the study was explained and verbal assent was obtained from the parents of each child.

\section{Statistical analysis}

Student's $t$-test was used to assess sex differences of mean anthropometric indices. Stunting, underweight and overweight/obesity were compared between sexes using a $\mathrm{X}^{2}$ test. In all analyses, $\mathrm{p}$ values less than 0.05 were considered statistically significant.

\section{RESULTS}

The majority of children came from relatively well-off families. The average family income of the children was more than eight thousand Rupees (Rs.8405.33, US\$163.51) per month. Approximately half (49.5\%) of the fathers were engaged in business and $24.6 \%$ worked in government sectors. The average number of persons per house was 3.3 and more than seventy percentage (72.6\%) of families had three persons (Table 1).

\begin{tabular}{|l|l|l|l|l|l|}
\hline Gender & No (\%) & Family size & No (\%) & Occupation & No (\%) \\
\hline Boys & $578(54.5)$ & Mean \pm SD & $3.3 \pm 0.55$ & Govt service & $261(24.62)$ \\
\hline Girls & $482(45.4)$ & $1-3$ persons & $770(72.64)$ & Private service & $195(18.39)$ \\
\hline & & $4-6$ persons & $285(26.8)$ & Business & $525(49.52)$ \\
\hline & & $>7$ persons & $5(0.47)$ & Labour & $54(5.09)$ \\
\hline & & & & Others & $25(2.35)$ \\
\hline
\end{tabular}

Table 1: Socio-economic and demographic features of the families 


\begin{tabular}{|c|c|c|c|c|c|c|c|c|}
\hline \multirow{2}{*}{$\begin{array}{l}\text { Age } \\
\text { (yrs) }\end{array}$} & \multirow{2}{*}{$\begin{array}{l}\text { Boys } \\
(\mathbf{n})\end{array}$} & \multirow{2}{*}{$\begin{array}{l}\text { Girls } \\
(\mathbf{n})\end{array}$} & \multicolumn{3}{|c|}{ Weight (kg) } & \multicolumn{3}{|c|}{ Height(cm) } \\
\hline & & & $\begin{array}{c}\text { Boys } \\
\text { Mean(SD) }\end{array}$ & $\begin{array}{c}\text { Girls } \\
\text { Mean(SD) }\end{array}$ & p-value & $\begin{array}{c}\text { Boys } \\
\text { Mean(SD) }\end{array}$ & $\begin{array}{c}\text { Girls } \\
\text { Mean(SD) }\end{array}$ & p-value \\
\hline 1. & 146 & 122 & $8.28(1.1)$ & $7.78(1.3)$ & $0.008^{*}$ & $69.19(4.1)$ & $66.79(4.5)$ & $0.008^{*}$ \\
\hline 2. & 237 & 206 & $10.38(1.7)$ & $9.84(1.5)$ & $0.007^{*}$ & $78.48(4.7)$ & $76.9(5.1)$ & $0.009^{*}$ \\
\hline 3. & 195 & 154 & $12.46(2.2)$ & $11.85(2.2)$ & $0.013^{*}$ & $88.76(5.1)$ & $87.25(5.5)$ & $0.089 *$ \\
\hline
\end{tabular}

Table 2: Mean anthropometric measurements of pre-school age children

The anthropometric characteristics of the pre-school age children are presented in Table 2. The total sample included 1,060 children with a mean age of $1.46 \pm 0.49$ years. Of these children, 578 (54.5\%) were boys and 482 (45.4\%) were girls. Overall, the mean values of weight (Boys $10.55 \pm 2.40 \mathrm{~kg}$; Girls $9.96 \pm 2.34 \mathrm{~kg}$ ) and height (Boys $79.60 \pm 8.86 \mathrm{~cm}$; Girls $77.65 \pm 9.27 \mathrm{~cm})$ were significantly higher in boys compared to girls $(\mathrm{p} \leq 0.05)$. However, there was no significant difference between sexes in mean height values of at 3 years of age. The children in this study had a mean height ranging from $69.19 \mathrm{~cm}$ to $88.76 \mathrm{~cm}$ in boys and $66.79 \mathrm{~cm}$ to $87.25 \mathrm{~cm}$ in girls. It is apparent from this table that the mean values of weight and height were progressively accelerating with increasing age.

The frequencies of underweight and stunting are presented in Table 3. The overall (age and sex combined) rates

\begin{tabular}{|c|c|c|c|c|c|c|c|c|}
\hline \multirow[t]{2}{*}{ Nutritional status } & \multicolumn{4}{|c|}{ Boys } & \multicolumn{3}{|c|}{ Girls } & \multirow[b]{2}{*}{ Total } \\
\hline & 1 yrs & 2 yrs & 3 yrs & Total & $1 \mathrm{yrs}$ & 2 yrs & 3 yrs & \\
\hline \multicolumn{9}{|l|}{ Weight-for-age ${ }^{a}$} \\
\hline$-3 \mathrm{SD}$ & 17(11.6) & $18(7.5)$ & $11(5.6)$ & $46(7.9)$ & $13(10.6)$ & $36(17.4)$ & $16(10.3)$ & $65(13.4)$ \\
\hline$-2 \mathrm{SD}$ & $30(20.5)$ & $51(21.5)$ & $44(22.5)$ & $125(21.6)$ & 19(15.5) & $3(1.4)$ & $46(29.8)$ & $68(14.1)$ \\
\hline Total & $47(32.1)$ & $69(29.1)$ & $55(28.2)$ & $171(29.5)$ & $32(26.2)$ & $39(18.9)$ & $62(40.2)$ & $133(27.5)$ \\
\hline \multicolumn{9}{|l|}{ Height-for-age ${ }^{b}$} \\
\hline$-3 \mathrm{SD}$ & $45(30.8)$ & $77(32.8)$ & $29(14.8)$ & $151(26.12)$ & $42(34.4)$ & $65(31.5)$ & $28(18.1)$ & $135(28.0)$ \\
\hline$-2 \mathrm{SD}$ & $27(18.4)$ & $59(24.8)$ & $51(26.1)$ & $137(23.7)$ & $23(18.8)$ & $48(23.3)$ & $41(26.6)$ & $112(23.2)$ \\
\hline Total & $72(49.3)$ & $136(57.3)$ & $80(41.0)$ & $288(49.8)$ & $65(53.2)$ & $113(54.8)$ & $69(50.6)$ & $247(51.2)$ \\
\hline
\end{tabular}

Table 3: Age specific prevalence of underweight and stunting among the pre-school age children
Figures in parentheses are percentages of the total in each column. ${ }^{\mathrm{a}} \mathrm{X}^{2}=9.901, \mathrm{df}=3, \mathrm{p}=0.0194 ;{ }^{\mathrm{b}} \mathrm{X}^{2}=2.704, \mathrm{df}=3, \mathrm{p}=0.4394$

\begin{tabular}{|c|c|c|c|c|c|c|}
\hline \multicolumn{7}{|c|}{ BMI classification } \\
\hline \multirow{2}{*}{ Age } & \multicolumn{3}{|c|}{ Thinness } & \multirow{2}{*}{ Normal } & \multirow{2}{*}{ Overweightb } & \multirow{2}{*}{ Obesity $^{c}$} \\
\hline & Moderate & Severe & Total $^{\mathrm{a}}$ & & & \\
\hline \multicolumn{7}{|l|}{ Boys } \\
\hline 1 & $51(34.9)$ & $4(2.7)$ & $55(37.6)$ & $54(36.9)$ & $27(18.4)$ & $10(6.8)$ \\
\hline 2 & $67(28.2)$ & $10(4.2)$ & $77(32.4)$ & $85(35.8)$ & $43(18.1)$ & $32(13.5)$ \\
\hline 3 & $70(35.8)$ & $25(12.8)$ & $85(43.5)$ & $69(35.3)$ & $26(13.3)$ & $15(7.6)$ \\
\hline Total & $188(32.5)$ & $39(6.7)$ & $217(37.5)$ & $208(35.9)$ & $96(16.6)$ & $57(9.8)$ \\
\hline \multicolumn{7}{|l|}{ Girls } \\
\hline 1 & $40(32.7)$ & $29(23.7)$ & $69(56.5)$ & $31(25.4)$ & $8(6.5)$ & $14(11.4)$ \\
\hline 2 & $67(32.5)$ & $7(3.3)$ & 74(35.9) & $78(37.8)$ & $36(17.4)$ & $18(8.7)$ \\
\hline 3 & $12(7.7)$ & $1(0.64)$ & $24(15.5)$ & $106(68.8)$ & $13(8.4)$ & $10(6.4)$ \\
\hline Total & $119(24.6)$ & $37(7.6)$ & $156(32.3)$ & $215(44.6)$ & $57(11.8)$ & $42(8.7)$ \\
\hline
\end{tabular}

Table 4: BMI classification of pre-school children 


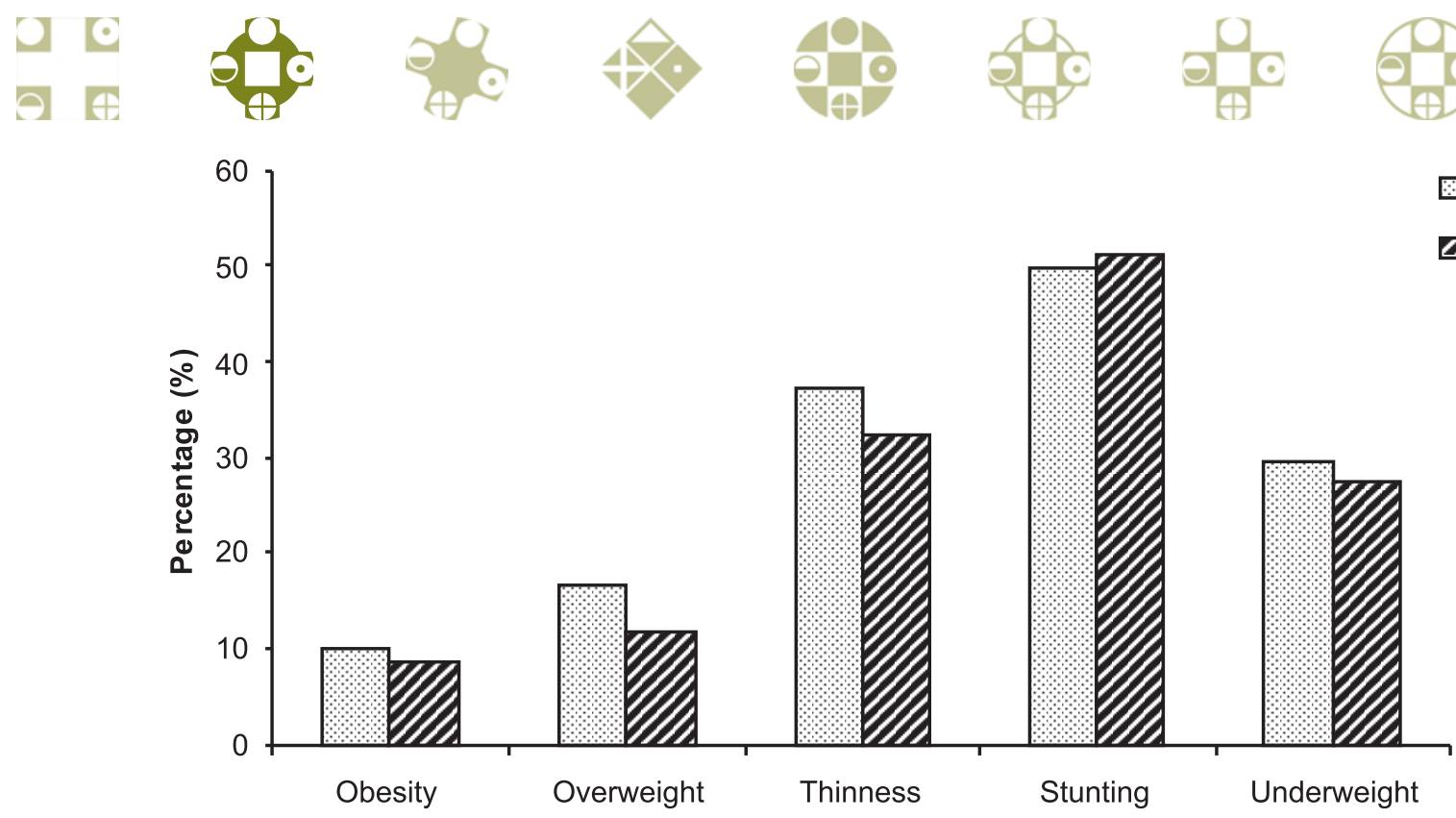

Fig. 1: Prevalence of overall malnutrition in urban Bengalee pre-school age children $(\mathrm{N}=1060)$.

of underweight and stunting were $28.6 \%$ and $50.9 \%$, respectively. The rate of underweight was higher among boys (underweight $=29.5 \%$ vs $27.5 \%$ ), but stunting was higher among girls (stunting $=49.8 \%$ vs $51.2 \%$ ). In both boys and girls, the highest percentages of stunting were exhibited at 2 years of age, followed by 1 and 3 years. Likewise, the extent of underweight decreased with increasing age in boys, but in girls the highest prevalence was observed in those 3 years of age. However, the extent of severe $(<-3 S D)$ underweight and stunting was comparatively higher among girls than boys. It is noted that the highest percentage of children were severely stunted.

Table 4 presents the BMI classification of participants according to gender and age. Overall, thinness affected approximately $35.1 \%$ of pre-school age children with most being moderate thinness $(28.9 \%)$. The overall rates of overweight and obesity were $14.4 \%$ and $9.3 \%$, respectively. Overweight was predominant at 2 years of age in both sexes. Normal BMI-for-age in boys and girls was $35.9 \%$ and $44.6 \%$, respectively.

Fig. 1 depicts the nutritional status of urban Bengalee pre-school age children stratified by gender. A noteworthy point is that obesity was slightly higher in girls but overweight was significantly different $(\mathrm{p}<0.05)$ between boys (16.6\%) and girls (11.8\%). Boys tended to have more thinness compared to girls, and the difference was statistically significant $(p<0.05)$. There was no significant difference between boys and girls in respect to stunting and underweight.

\section{DISCUSSION}

Malnutrition makes its principal impact on pre-school age children in developing countries. These nations face great difficulties in improving the standards of living of its population because of unequal distribution of its resources leading to widespread malnutrition. ${ }^{[21]}$ There is a consen- sus that a wide variety of biological, behavioural and socioeconomic variables influence the health status of children in developing countries. ${ }^{[24]}$

The present study revealed that the major type of malnutrition was the seemingly high prevalence undernutrition (stunting and underweight) among the pre-school age children living in urban areas of Midnapore. In this study the overall prevalence of underweight was $28.6 \%$ among pre-school age children based on the 2007 WHO classification. Many studies in India ${ }^{[19]}$ and West Bengal ${ }^{[20]}$ have indicated a higher prevalence of underweight in pre-school age children. That a very high proportion (more than 50\%) of children in this study was stunted is surprising.; stunting was more prevalent in two year old children of both sexes. Although it is well known that the prevalence of stunting is maximum in the first two to three years of life (due to high velocity of linear growth), certain reports have suggested that it varies by region. ${ }^{[20]}$ There is sufficient evidence to demonstrate that the children in the general population of developing countries are markedly stunted. ${ }^{[25,26]}$ NFHS-3 indicates that approximately $46 \%$ of children under 5 years of age were moderately to severely underweight and that $38 \%$ were moderately to severely stunted. ${ }^{[5]}$ In a study performed in different areas of Punjab, it was found that the prevalence of underweight and stunting was $55.6 \%$ and $40.9 \%$, respectively. ${ }^{[2]}$ Compared to our study, the prevalence of stunting were lower. In general, stunting and underweight are comparatively higher among Indian children ${ }^{[26]}$ Although determination of the main causal factors for stunting is beyond the scope of this study, Ying et al ${ }^{[25]}$ mentioned that the high prevalence of stunting among pre-school age children is most likely related to environmental factors, mainly nutrition and slower socioeconomic development.

In this study, a significant difference between the two sexes with regard to prevalence of undernutrition was not found. However, prevalence of underweight was more pronounced in boys and stunting was more pronounced 
in girls. These findings support of previous observations. This concurs with the results of our previous study performed in rural areas of Kharagpur, West Bengal by Chatterjee \& Paul. ${ }^{[19]}$ In general, it was observed that boys suffer less undernutrition than girls (NFHS, 1998-99). ${ }^{[4]}$

In this study, BMI-for-age was utilised as an indicator of thinness and overweight. The WHO expert committee ${ }^{[22]}$ has recommended BMI-for-age as the best indicator to assess undernutrition (thinness) or overweight. Thinness usually describes acute malnutrition. Table 4 shows the prevalence of thinness was $35 \%$ and was higher among boys $(37.5 \%)$ than girls $(32.3 \%)$. When the prevalence of thinness between boys and girls of each age was compared, the differences were statistically significant $(\mathrm{p}<0.05)$. A similar trend was reported by Bisai \& Manna ${ }^{[27]}$ who conducted a study in the urban area of West Bengal and showed that approximately $47 \%$ of the pre-school age children suffered thinness according to the Cole et. al. classification.

The present study demonstrated the alarmingly higher prevalence of overweight (14.4\%) and obesity (9.3\%) among the Bengalee pre-school age children. This rate were much higher than that found in previous studies conducted in different parts of India. ${ }^{[6-8]}$ Increasing obesity is already a major concern for pre-school age children in developed countries ${ }^{[12]}$ as well as urban India. ${ }^{[6,7]}$ Affluence and urban lifestyle are associated with a higher prevalence of overweight in lower and middle income developing countries. ${ }^{[28]}$

This study provides evidence that stunting concurrent with overweight or obesity is an important public health problem among urban pre-school aged children in West Bengal, and it is in agreement with previous studies that show stunting is associated with overweight in children of developing nations that are undergoing nutritional transition..$^{[9-11]}$

The interpretation of our findings indicates that both undernutrition and overnutrition coexist in our study areas among pre-school age children. Few studies have reported the presence of obesity and growth retardation within the same children. ${ }^{[9,10]}$ Wang et al ${ }^{[9]}$ mentioned that it is a major public health problem that is most likely growing and should be given due attention. The "nutrition paradox" ${ }^{[29]}$, the coexistence of nutritional deficit and excess, underlines the difficulty of designing interventions aimed at reducing undernutrition while addressing the increasing problem of overweight and obesity at the same time. Future studies should address causes of overnutrition and undernutrition among Bengalee pre-school age children. There is an urgent need to address nutrition problems among pre-school age children in developing countries, without neglecting urban areas.

\section{ACKNOWLEDGEMENTS}

We are indebted to the staff of Midnapore Red Cross Hospital for their cooperation throughout the data collection period. The authors gratefully acknowledge the assistance of Mr. Sanjay Kr. Kundu.

\section{REFERENCES}

1. FAO: The double burden of malnutrition: Case studies from six developing countries. FAO Food and nutrition paper No84, Rome 2000.

2. Muller O, Krawinkel M. Malnutrition and health in developing countries. CMAJ 2005; 173(3):279-86.

3. Ramalingaswami V, Johnsson U, Rohde J. The Asian Enigma. Progress of Nations New York: United Nations Children's Fund; 1996.

4. Kanjilal B, Guha Mazumdar P, Mukherjee M, Hafizur Rahman M. Nutritional status of children in India: household socio-economic condition as the contextual determinant. International Journal for Equity in Health 2010; 9:19.

5. International Institute for Population Sciences (IIPS) \& ORC MACRO: National Family Health Survey (NFHS-3), 2005-06: India Mumbai: IIPS 2007.

6. Harsha Kumar HN, Mohanan P, Kotian S, Sajjan BS, Ganesh Kumar S. Prevalence of overweight and obesity among pre-school children in semi urban South India. Indian Pediatr 2008; 45(17):497-99.

7. Kaur N, Kaur Sidhu S, Sidhu S. Prevalence of overweight and obesity in preschool children of Amritsar, Punjab. Anthropologist 2010; 12(3):221-24.

8. Kaur PN, Marwaha G, Sidhu S. Growth pattern of affluent school children of Amritsar. Anthropologist 2005; 7(4):261-64.

9. Wang X, Hojer B, Guo S, Luo S, Zhou W, Wang Y. 'Stunting' and 'overweight' in the WHO child growth standards-malnutrition among children in a poor area of China. Public Health Nutrition 2009; 12(11):1991-98.

10. Fernald LC, Neufeld LM. Overweight with concurrent stunting in very young children from rural Mexico: prevalence and associated factors. European Journal of Clinical Nutrition 2007; 61:623-32.

11. Duran P, Caballero B, de Onis M. The association between stunting and overweight in Latin American and Caribbean preschool children. Food and Nutrition Bulletin 2006; 27(4): 300-05.

12. Cattaneo A, Monasta L, Stamatakis E, Lioret S, Castetbon K, Frenken F et al. Overweight and obesity in infants and pre-school children in the European Union: a review of existing data. Obes Rev 2010; 11(5):389-98.

13. Eiben OG. Growth and maturation problems of children and social inequality during economic liberalization in central and Eastern Europe. pp 76-95. In: Human Biology and Social Inequality. S. S. Strickland and P. S. Shetty (Eds.): Cambridge University Press Cambridge, 1998.

14. SCN (United Nation Standing Committee on Nutrition), Fifth report on the World Nutrition Situation: Nutrition for improved development outcomes, SCN, Geneva, Switzerland, 2004.

15. Pelletier DL, Frongillo EA. Changes in child survival are strongly associated with changes in malnutrition in developing countries. J Nutr 2003, 133:107-19. 
16. de Onis M, Monteiro C, Akre J, Clugston G. The worldwide magnitude of protein- energy malnutrition: an overview from the WHO Global Database on child growth. Bulletin of the World Health Organization 1993; 71:703-12.

17. de Onis M, Blossner M. The World Health Organization Global Database on Child Growth and Malnutrition: methodology and applications. International Journal of Epidemiology 2003; 32:518-26.

18. Grover K, Singh I, Jain R. Anthropometric profile of rural preschool children belonging to different agroclimatic regions of Punjab. Anthropologist 2009; 11(1): 25-30.

19. Chatterjee S, Paul SP. Prevalence of malnutrition in pre-school children of rural Kharagpur. Indian Journal of Physiology \& Allied Sciences 1992; 46(1):37-46.

20. Jyothi Lakshmi A, Begum K, Saraswathi G, Prakash J. Nutritional status of rural preschool children-mediating factors. The J Family Welfare 2003; 49(2):45-56.

21. Kaur G, Singh Kang H, Singal P, Singh SP. Nutritional status: anthropometric perspective of pre-school children. Anthropologist 2005; 7(2):99-103.

22. World Health Organization. Physical Status. The Use and Interpretation of Anthropometry. Technical Report Series No. 854. Geneva: World Health Organization, 1995.
23. World Health Organization Multicentre growth references study group. WHO child growth standards: Length/height-for-age, weight-for-age, weight-forlength, weight-for-height and body mass index-for-age: Methods and development. Geneva: WHO, 2006.

24. Rutstein SO. Factors associated with trends in infant and child mortality in developing countries during the 1990s, Bulletin of the World Health Organization 2000; 78: 1256-70.

25. Ying C, Fengying Z, Wenjun L, Keyou G, Daxun J, de Onis M. Nutritional status of preschool children in poor rural areas of China. Bulletin of the World Health Organization 1994; 72 (1):105-11.

26. Agarval KN, Agarwal DK, Benakappa DG et al. Growth performance of affluent Indian children (under-fives). Growth standard for Indian children. New Delhi, Nutrition Foundation of India, 1991 (Scientific Report No. 11).

27. Bisai S, Manna I. Prevalence of thinness among urban poor pre-school children in West Bengal, India. Sudanese J Pub Health ; 193:98.

28. Popkin BM, Gorden-Larsen P: The nutritional transition: world wide obesity dynamics and their determinants. Int J Obes Relat metab Disord 2004; 28(suppl 3):S2-9.

29. Caballero B. A nutrition paradox-underweight and obesity in developing countries. N Engl J Med 2005; 352:1514-6. 